International Journal of Automotive and Mechanical Engineering (IJAME)

ISSN: 2229-8649 (Print); ISSN: 2180-1606 (Online); Volume 8, pp. 1416-1429, July-December 2013

CUniversiti Malaysia Pahang

DOI: http://dx.doi.org/10.15282/ijame.8.2013.29.0117

\title{
EFFECT OF COMPRESSED NATURAL GAS MIXING ON THE ENGINE PERFORMANCE AND EMISSIONS
}

\author{
T. Yusaf ${ }^{1,2}$, P. Baker ${ }^{1}$, I. Hamawand ${ }^{2}$ and M.M. Noor ${ }^{1}$ \\ ${ }^{1}$ Computational Engineering and Science Research Centre, School of Mechanical and \\ Electrical Engineering, University of Southern Queensland (USQ), Australia \\ ${ }^{2}$ National Centre for Engineering in Agriculture, USQ, Australia \\ Email: Talal.Yusaf@usq.edu.au, Muhamad.MatNoor@usq.edu.au
}

\begin{abstract}
Cleaner air quality is becoming a global concern, thus to improve the fuel and combustion process is vital. In this paper, computational fluid dynamics (CFD) analysis software CFD-ACE is used to investigate the flow behavior of methane and air in a compressed natural gas (CNG)-air mixer to be implemented in a $\mathrm{CNG-diesel} \mathrm{dual-fuel}$ stationary engine. The effect of the number of mixer holes on the mixture quality was evaluated. The results of the 3D CFD simulation showed that the 8-hole Venturi mixer gave superior performance compared to the 4-hole mixer. Further analysis was carried out on the 8-hole Venturi mixer to investigate the effect of engine speed on the mass flow rate of CNG and the equivalence air to fuel ratio $(1 / \lambda)$. The second half of the paper presents comparative performance results between a single cylinder research compression ignition (CI) engine fueled with a CNG-diesel system and a conventional $\mathrm{CI}$ engine fueled by conventional diesel. The engine was equipped with the simulated 8 hole Venturi mixer. The result showed a significant reduction in exhaust gas emission components $\left(\mathrm{NO}_{\mathrm{x}}, \mathrm{CO}\right.$ and $\left.\mathrm{CO}_{2}\right)$ from the $\mathrm{CNG}$-diesel engine compared to the conventional diesel engine, i.e. the reduction rates were on average of $54 \%, 59 \%$ and $31 \%$ respectively. The average power output developed by the dual-fuel engine was $10 \%$ higher than the diesel over the power curve.
\end{abstract}

Keywords: Compressed natural gas; gas-mixer; computational fluid dynamics; dual-fuel engine; gas emission.

\section{INTRODUCTION}

Public health related to environmental air pollution is of major concern globally. Recently one of the major challenges relating to diesel emissions is the link between very fine particulate exhaust emissions, $\mathrm{PM}_{2.5}$, and respiratory diseases. Studies have found that long-term exposure to fine particulate exhaust emissions leads to a higher risk of lung and cardiopulmonary mortality (Brook et al., 2002; Azad, Ameer Uddin, \& Alam, 2012; Kalyani Radha, Naga Sarada, Rajagopal, \& Nagesh, 2011; Yanagisawa et al., 2003; Mohanamurugan, \& Sendilvelan, 2011). One of the fields of research currently undertaken to address this problem is the use of alternative "clean" fuels. One such fuel which has shown great promise in reducing emissions in general and fine particulates specifically is compressed natural gas (CNG) (Das, 1995; Holmen \& Ayala, 2002; Sukh, Graham, \& Striebich, 2001; Mat Yasin, Mamat, Sharma, \& Yusop, 2012). The properties of CNG as an alternative fuel for internal combustion engines have been well documented (Heywood, 1988; Bhaskar, Nagarajan, \& Sampath, 2010; Sundar Raj, \& Sendilvelan, 2010; Yusaf et al., 2010; Ghobadian, Najafi, \& Nayebi, 2013). 
Properties such as very high hydrogen to carbon atom ratio, 4:1 compared to $1.63: 1$ for diesel (Ingersoll, 1996), a very high octane rating (OR) with a research octane number (RON) in the vicinity of 130 depending on composition (Das, 1995; Ingersoll, 1996; Kamil, Rahman, \& Bakar, 2011) and wider ignition limits allowing a leaner burn (Tao $\&$ Mei, 2004), are some of the properties that make it an attractive clean substitute for diesel fuel. It has been demonstrated that CNG can significantly reduce combustion emissions (Heywood, 1988; Das, 1995; Ingersoll, 1996; Xu \& Furuyama, 1997; Akansu et al., 2004; Mello et al., 2006; Li \& Yau, 2008; Yusaf et al., 2009, 2010; Aziz, Farmansyah, \& Shahzad, 2010; Suthawaree et al., 2012; Zhang et al., 2013, which include particulates, but ultrafine particulates and $\mathrm{NO}_{\mathrm{x}}$ have proven to be more elusive and have been the subject of a great deal of research effort in recent times (Sukh et al., 2001; Holmen \& Ayala, 2002; Carlucci et al., 2008; Yusaf et al., 2010).

A number of methods have been developed to reduce particulate and $\mathrm{NO}_{\mathrm{x}}$ emissions in diesel engines. The dual-fuel with mixing process is one of these methods (Yusaf et al., 1996; Lin \& Su, 2003; Selim, 2004; Kapilan, Ashok Babu, \& Reddy, 2010). Some earlier researchers designed and studied the gas mixer to mix the fuel (Gourara et al., 2006; Noor, Wandel, \& Yusaf, 2008; Ramasamy et al., 2008). One very practical method of converting a diesel engine to accept CNG without major modifications is to fit a CNG-diesel dual-fuel system to the engine intake and, if necessary, reduce the compression ratio to suit the octane rating of the CNG (Yusaf et al., 1996, 2010; Rahim, Mamat, Taib, \& Abdullah, 2012). With this arrangement, the air/fuel mixer can be used to admit a mixture of air and CNG into the combustion chamber prior to compression (Noor et al., 2008), while a small amount of diesel fuel is injected to ignite the air/CNG homogeneous charge and maintain combustion within the chamber. The purpose of the Venturi mixer is to admit the CNG into the air stream in a manner that achieves efficient mixing (Noor et al., 2008), and to regulate the air/fuel ratio with the assistance of a butterfly valve in the CNG supply line or a pressure regulator upstream of the mixer (Yusaf et al., 1996). With this dual-fuel system, the proportions of CNG and diesel can be varied between the limits of straight diesel at one extreme and a high proportion of CNG and minimal diesel at the other (Yusaf et al., 1996, 2000, 2010). With a CNG-diesel dual-fuel system, good air/CNG mixing is critical for efficient combustion and low emissions. The objective of the current research is to optimize a mixer design and test it to achieve minimal emissions at a variety of mapping points. The current work is divided into two parts:

i. In the first part, computational fluid dynamics (CFD) analysis software (CFDACE) was used to investigate the mixing performance of CNG and air in a Venturi-type mixer. The objective is to optimize the mixer design to produce a homogeneous air/fuel mixture. Two different designs were investigated, (a) a Venturi with four holes at the throat and (b) one with eight holes at the throat. The effect of engine speed on the equivalence ratio $(1 / \lambda)$ was also investigated.

ii. The second part of this paper includes experimental work using a single cylinder research compression ignition $(\mathrm{CI})$ engine. The work aimed to compare the engine performance and emission using a CNG-diesel system of an 8-hole Venturi mixer with the conventional CI engine with $100 \%$ diesel fuel. 


\section{DESIGN OF CNG-AIR MIXER}

The purpose of a CNG-air mixer is to mix a predetermined amount of CNG fuel with air before admission into the combustion chamber. Mishra (2007) studied the flame stability limit for CNG-air premixed combustion. Research has shown that the mixing of co-flowing gases can be problematic (Das, 1995; Baker, 2009). Co-flowing gases can flow side-by-side for quite some distance with very little sign of bulk mixing. The two dominant mechanisms of gas mixing are:

i. Diffusion. Gases above absolute zero with active motion of their molecules will obey Fick's laws of diffusion. Due to the random motion of the molecules of both gas species, they will gradually diffuse into each other. This process is dependent on partial gas pressures of each species and diffusivity of the gasses, where diffusivity is a function of gas temperature and viscosity. The higher the temperature and the greater the concentration gradient, the greater the diffusion flux.

ii. Bulk mixing due to turbulence within the gas flow. The greater the level of turbulence, the greater the bulk mixing effect. Turbulence can be created in a number of ways: the higher the flow velocity, the greater the turbulence as indicated by the Reynolds number. Turbulence can also be achieved by flow path geometry. Sharp bends, sharp changes in cross-sectional area and obstacles can create shear within the flow, creating fine and large scale turbulence. The other factor which assists mixing is residence time in the induction system. The longer the induction runner system, the greater the opportunity for mixing. Due to the very short residence time, air/fuel mixing relies heavily on turbulence within the induction system and good initial air/fuel distribution within the mixer. Typically, a diesel under most conditions will be operating on the lean side of stoichiometric. This excess of air will favor high combustion efficiencies, but for very lean mixtures efficient mixing is critical for complete combustion.
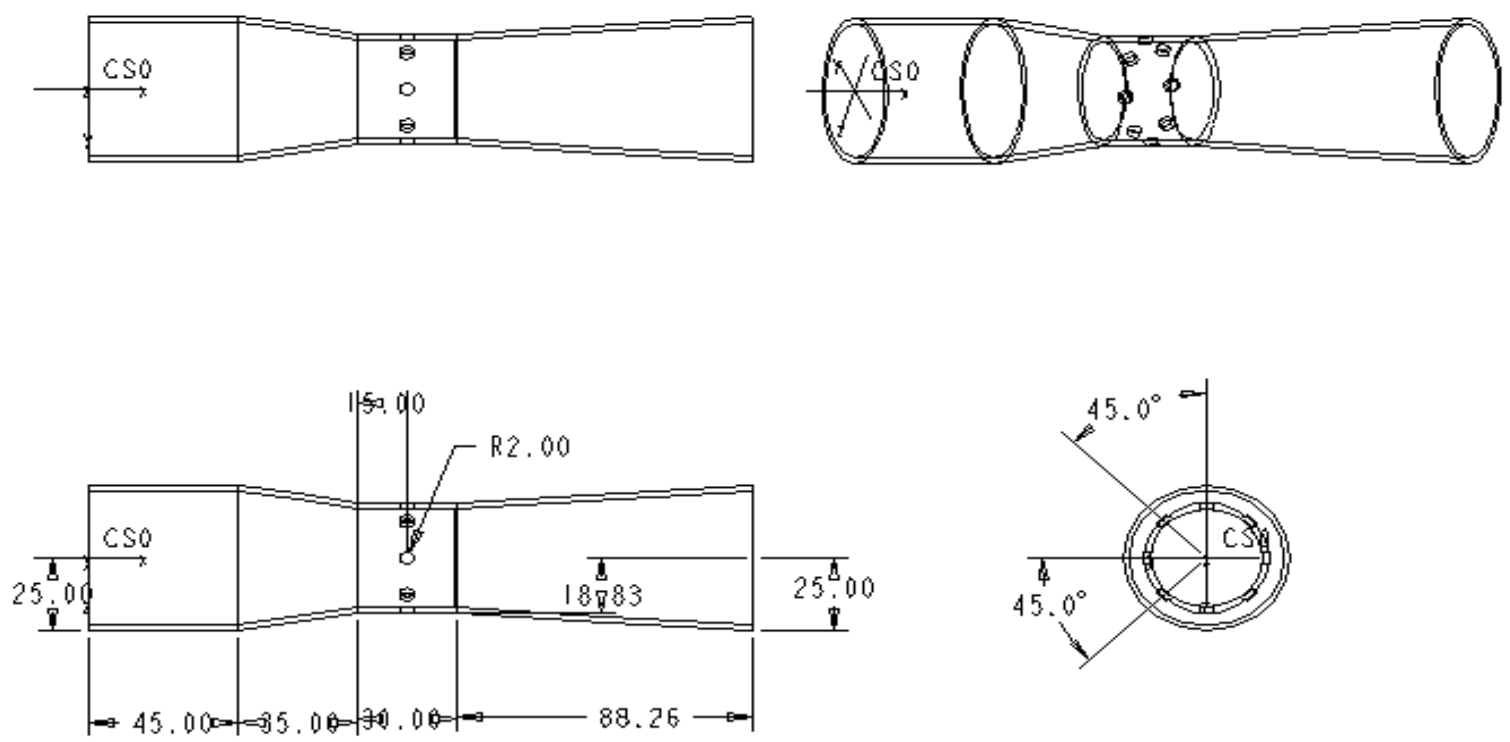

Figure 1. Details of the 8-hole Venturi mixer used in the CFD modeling. 
The mixer that was designed and constructed in the present work is a Venturi type (Figure 1). Air enters the mixer through the main inlet and CNG enters through small holes located at the throat at a 90 degree angle to the air flow through the Venturi. The $4 \mathrm{~mm}$ diameter holes are distributed evenly circumferentially at the throat.

\section{CFD SIMULATION}

The CFD technique is based on the numerical solutions of the fundamental governing equations of fluid dynamics, namely the continuity, momentum and energy equations. CFD has previously been successful in solving many complex engineering problems that are difficult to analyze experimentally (Dally, Fletcher, \& Masri, 1998; Fletcher et al., 2000; Baukal et al., 2001; Davidson, 2002; Wandel, Smith, \& Klimenko, 2003; Najiha et al., 2012a, 2012b; Noor et al, 2012a, 2012b). The CFD-ACE+ software package was used for the current work to accomplish the job. The CFD-ACE flow solver is a finite volume, pressure based, fully implicit code solving the 3D NavierStokes equations governing fluid flow and associated physics. The code is used for the modeling of a wide range of industrial problems involving fluid flow, heat transfer (including radiation), turbulence, mixing of chemical species, multi-step chemistry, two-phase flows, moving/rotating bodies and other complex physics. In the present study, multi-block structured mesh is used in all the simulations. The assumptions made in the simulations are as follows:

i. Turbulent flow - This involves the use of a turbulence model, which generally requires the solution of additional transport equations. The k- $\varepsilon$ transport equation (Jones \& Launder, 1972; Launder \& Sharma, 1974) was used in the study. This model was practical for many flows and relatively simple to implement and easy to converge. Three quantities, turbulent kinetic energy (K), dissipation rate (D) and length scale (L), are very important in specifying the turbulence characteristics at the inlet. If $\mathrm{K}$ and $\mathrm{D}$ values are specified, the value for $\mathrm{L}$ is ignored. It is sometimes more convenient to provide a length scale instead of a value for the dissipation rate. The length scale that would be used for an internal flow is usually the inlet diameter or height.

ii. Mixing flow without reaction - This requires the solution of additional equations for mixture fractions or species mass fraction. In this simulation, it is assumed that there is no reaction between air and natural gas.

iii. Incompressible - As the speed involved is reasonably low, it is adequate to assume that the fluids are incompressible. With incompressible flow, the density of fluids is constant and it activates a pressure correction equation.

iv. Air inlet boundary - It is assumed that the conditions at the inlet boundary are fixed. For the fixed velocity condition, the flow solver determines the mass flow rate applied to each face of the boundary using the velocity specification, along with the pressure, temperature and density.

v. CNG inlet boundary - Fixed static pressure inlet boundary conditions are used at the fuel inlets. By using this boundary condition type, the mass of the fuel inducted into the Venturi will form part of the solution. Fuel will be inducted into the Venturi because of the low pressure created at the throat.

vi. Outlet boundaries - The fixed pressure outlet boundary conditions serve to anchor the system pressure and allow both inflow and outflow to satisfy continuity in the domain. Since fixed pressure outlet boundaries can also allow inflow, it is 
important to provide realistic values of turbulence quantities, temperature and mixture at these boundaries even though they are not required. These values are only used to evaluate diffusion at the boundary.

In order to check the accuracy and consistency of the simulation, a simple case of air-flow in the Venturi was simulated. Figure 2 shows the contours of pressure distribution at the mid plane and the pressure variation on the axis of symmetry. In this simulation, the inlet velocity was set at $1.5 \mathrm{~m} / \mathrm{s}$, whereas the exit pressure was set at -10 $\mathrm{Pa}$. The predicted pressure at the throat is $-11.8 \mathrm{~Pa}$ which agrees very well with the value given by application of the Bernoulli equation.

\section{The Effect of Number of Holes on Mixing Efficiency}

It has already been stated that mixing efficiency has a big influence on combustion efficiency. High combustion efficiency produces low exhaust gas emission components. In a dual-fuel engine, the mixer should be designed to be able to produce a lean air-fuel mixture, as the diesel engine is of the compression ignition type running on the lean side. It is highly likely that a rich mixture of CNG will produce incomplete combustion when it mixes with diesel. Incomplete combustion will produce high amounts of $\mathrm{CO}$, which is hazardous to the environment. Moreover, the excess air may lead to high $\mathrm{NO}_{\mathrm{x}}$ emission.
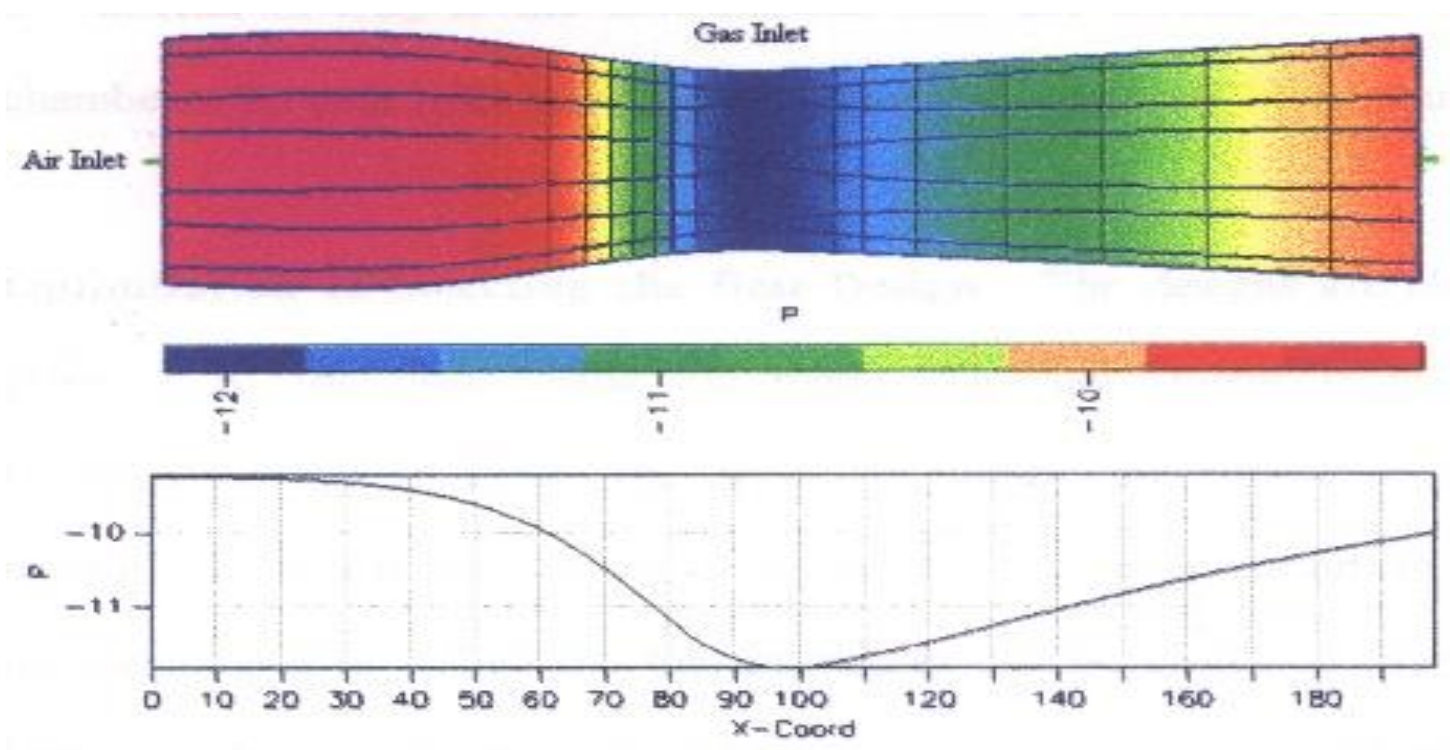

Figure 2. Pressure profile along the Venturi for the simple air flow case.

The corresponding diagram for the 8-hole Venturi is shown in Figure 4. When comparing the two Venturis, it can be seen that the mixing is more homogeneous for the 8-hole mixer. The mixing for the 4-hole Venturi is sluggish and is still mixing at exit from the Venturi. However, for the 8-hole mixer, the concentration ratio reached equilibrium a short distance downstream from the throat. The amount of CNG injected in the two mixers is also not the same. For the 4-hole Venturi mixer, the total amount of CNG injected is $0.197 \mathrm{~g} / \mathrm{s}$ compared to $0.079 \mathrm{~g} / \mathrm{s}$ for the 8-hole mixer, assuming they both have the same cross-sectional area. The mixing quality for the 4- and 8- hole Venturi has been investigated using CFD. The simulation was done for the same air 
inlet velocity and same outlet pressure of the real engine geometry. The inlet velocity of the air was determined theoretically.

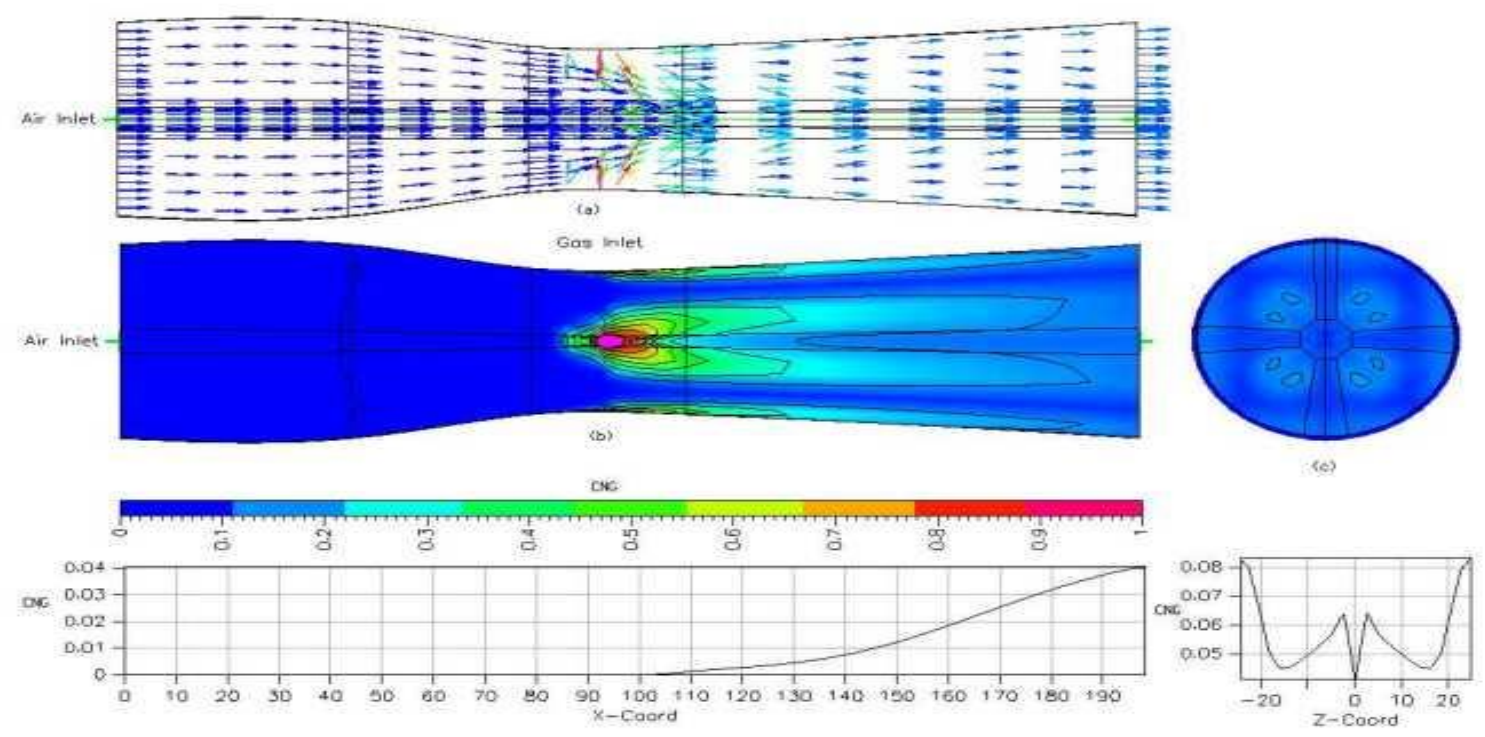

Figure 3. Concentration distribution of $\mathrm{CNG}$ for the 4-hole Venturi, inlet air velocity 1.5 $\mathrm{m} / \mathrm{s}$ and outlet pressure $-10 \mathrm{~Pa}$. Flow is turbulent.
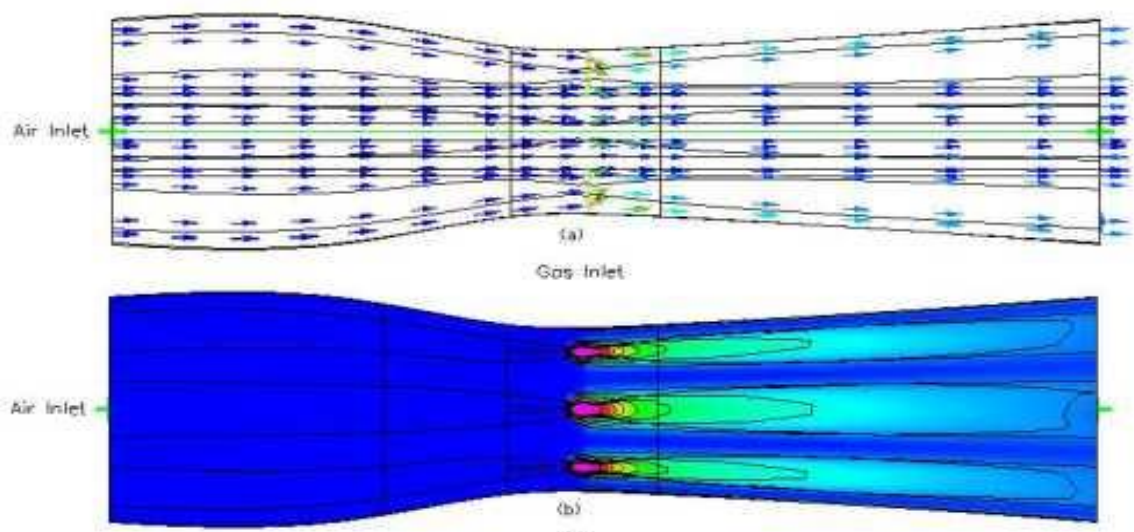

ace

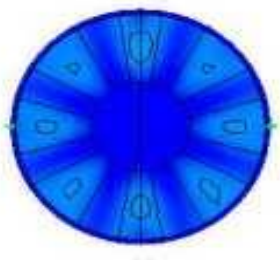

\{c\}
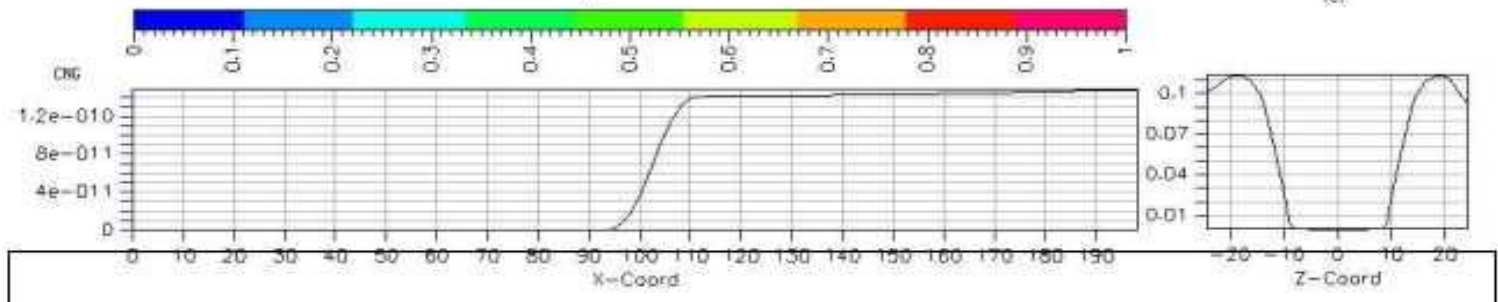

Figure 4. Concentration distribution of CNG for the 8-hole Venturi, inlet air velocity is set at $1.5 \mathrm{~m} / \mathrm{s}$ and outlet pressure at $-10 \mathrm{~Pa}$. Flow is turbulent.

The inlet velocity is dependent on the engine speed. The air inlet cross-sectional area and the total CNG cross-sectional area are constant, and the ratio was around 17:1. In order to investigate the effect of engine speed on the air/fuel ratio and mixing efficiency, further simulations were carried out using the 8-hole Venturi mixer. As the 
engine speed increases, velocity increases at the throat, increasing the depression. This increased depression will "suck" more fuel through the Venturi, automatically compensating for increased air flow rate through the Venturi. The distribution of CNG concentration through the mixer for engine speeds of $250 \mathrm{rpm}, 500 \mathrm{rpm}, 750 \mathrm{rpm}$ and $1000 \mathrm{rpm}$ was simulated. The simulated results showed that as the engine speed increases, the amount of CNG inducted into the mixer increases. Further analysis of CNG concentration at the exit of the mixer revealed that the air-fuel ratio decreases and hence the equivalence ratio increases with engine speed. The model showed that the mixing efficiency improved with engine speed due to an increase in flow turbulence.

\section{Engine Modification and Experimental Procedure}

The second part of this project included modifying an existing four-stroke singlecylinder diesel engine to be operated using a dual-fuel system. The most practical way of converting a diesel engine to accept $\mathrm{CNG}$ is by installing a CNG-air mixer at the air inlet before the combustion chamber. The engine specification is presented in Table 1.

Table 1. Engine Specification

\begin{tabular}{ll}
\hline \multicolumn{1}{c}{ Parameters } & \multicolumn{1}{c}{ Description } \\
\hline Model & Y 170 vertical 4 st diesel engine \\
Bore and length & $70 \mathrm{~mm} * 55 \mathrm{~mm}$ \\
Compression ratio & $16: 1$ \\
Displacement & $211 \mathrm{cc}$ \\
Maximum power & $3.5 \mathrm{~kW}$ \\
Injection timing & $14^{\circ} \mathrm{btdc}$ \\
\hline
\end{tabular}

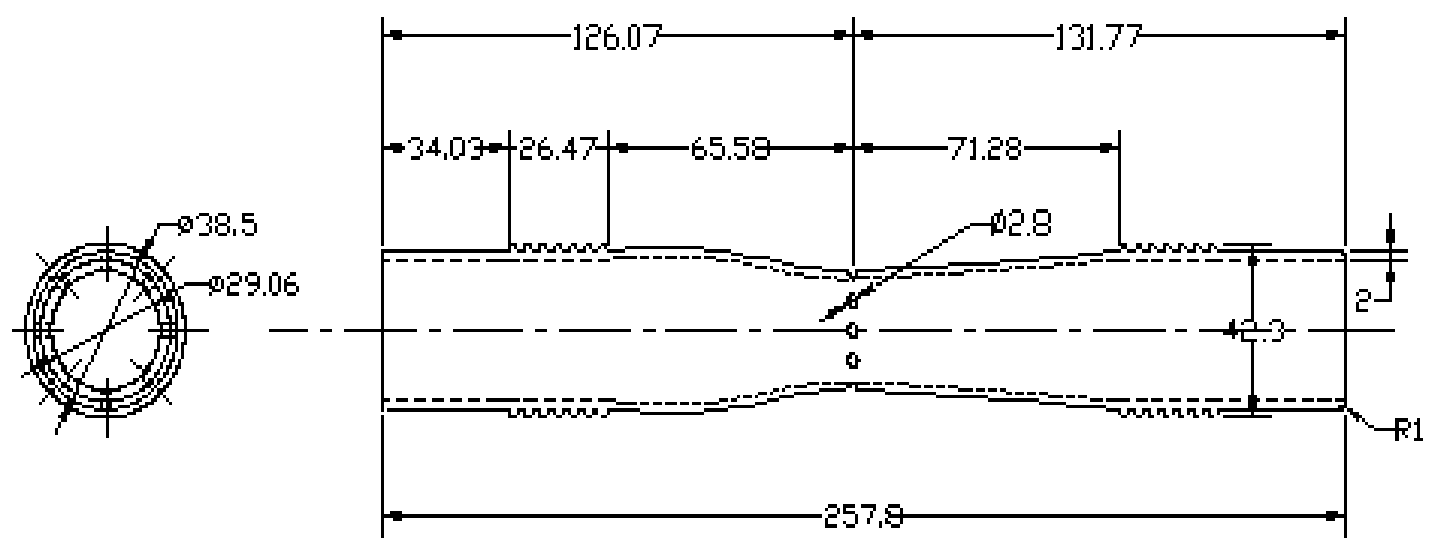

All dimensions are in $\mathrm{mm}$

Figure 5. Design of the Venturi mixer used for engine tests.

In this arrangement, the CNG will be admitted into the combustion chamber along with the air intake charge, while the diesel is used as a pilot in maintaining the 
flame inside the combustion chamber. Some minor modifications were made to the engine while the compression ratio remained unchanged. The design of the Venturi mixer (Figure 5) used in this study was based on the CFD study as mentioned above. An eddy-current dynamometer was used to apply variable torque to test the ability of the engine to produce power. An exhaust gas analyzer was employed to study the concentration of exhaust gases components. The engine test bed is shown schematically in Figure 6.

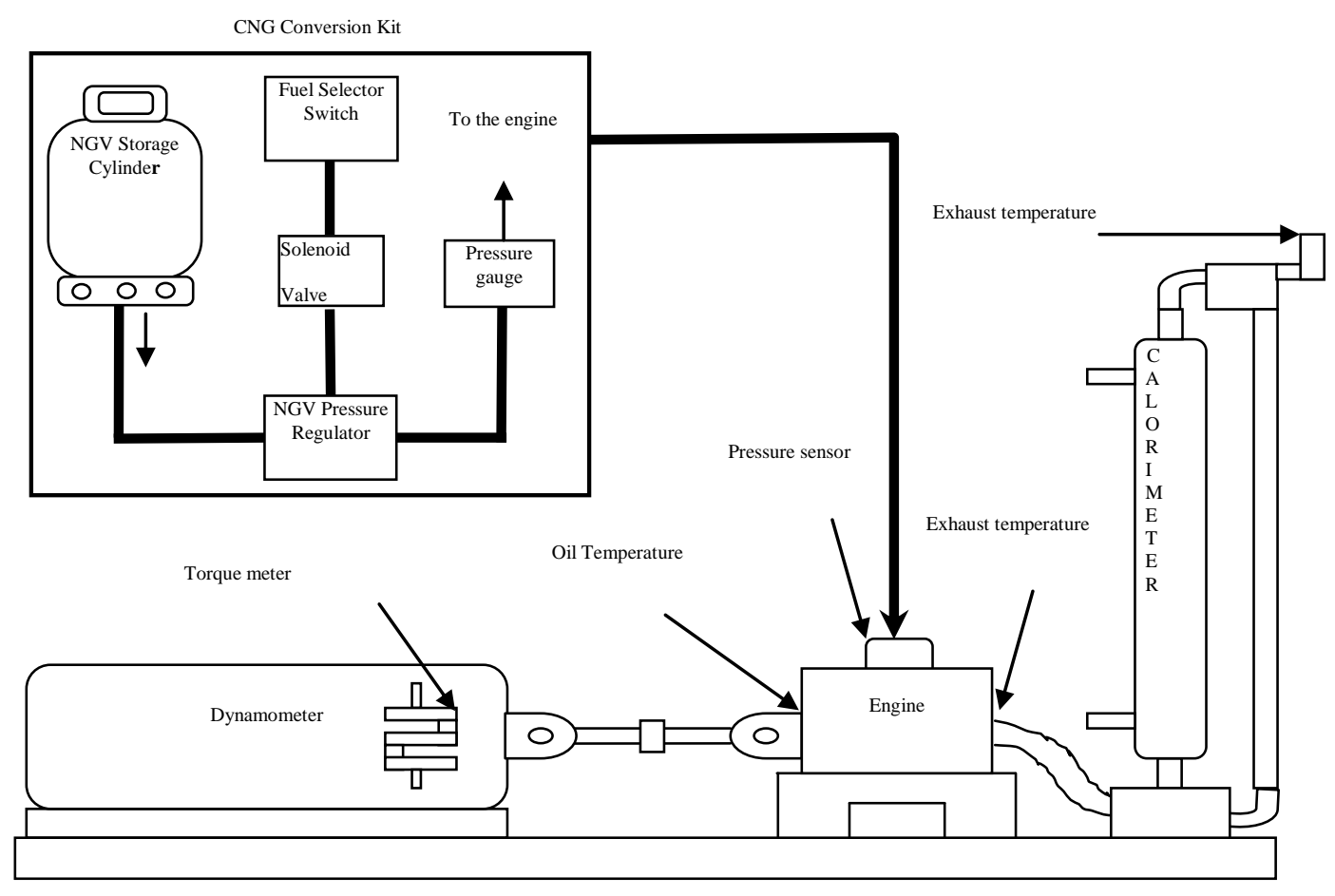

Figure 6. Schematic of experimental test bed

\section{Power Characteristics}

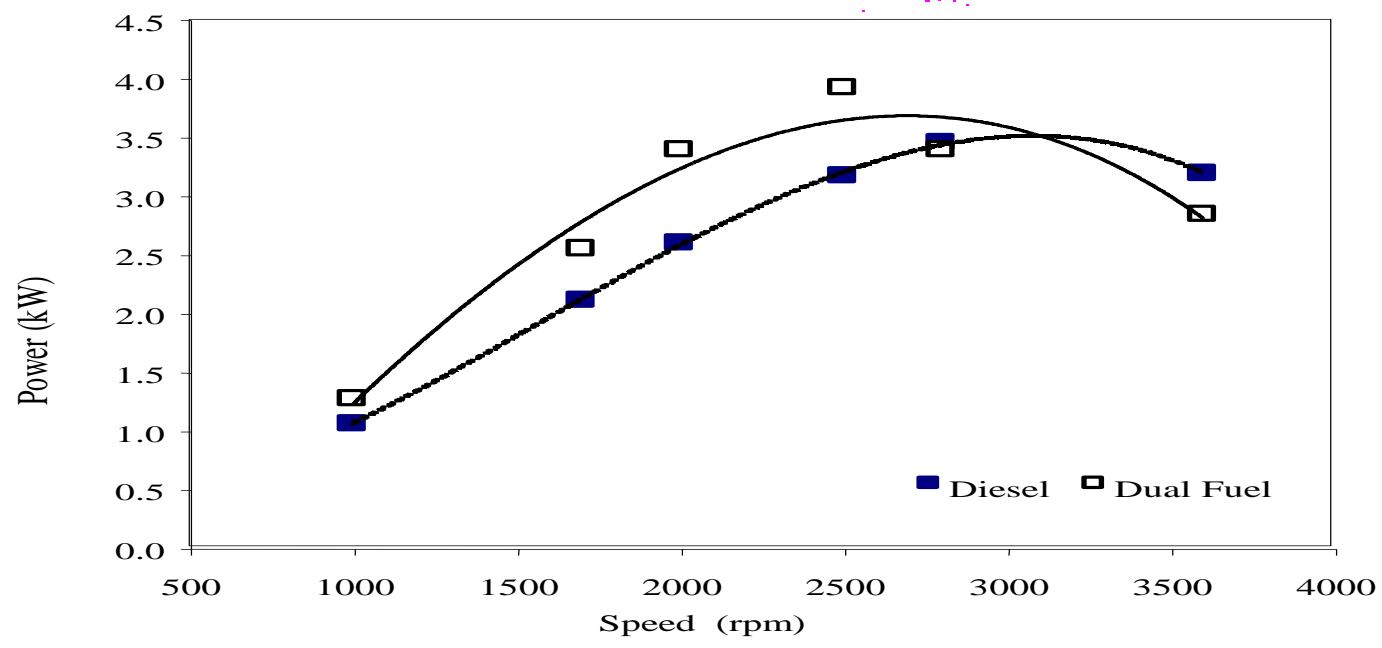

Figure 7. Power characteristics of the engine at maximum load operating conditions 
From the results of the study it was found that the dual-fuel system produced higher power than the diesel system, at engine speeds up to $3000 \mathrm{rpm}$. Maximum power of $4.0 \mathrm{~kW}$ was achieved at $2700 \mathrm{rpm}$ and dropped off as expected due to the increase in engine friction power. This trend was observed for both dual-fuel and diesel, as shown in Figure 7. At engine speeds beyond $3000 \mathrm{rpm}$, the power output from the diesel proved superior to the dual-fuel engine due to increased resistance to intake flow through the Venturi restriction and to the onset of knock, resulting from the rapid incylinder pressure rise due to combustion.

\section{RESULTS AND DISCUSSION}

\section{Oxides of Nitrogen}

Figure 8 compares the relationship between $\mathrm{NO}_{x}$ emission and engine speed for diesel and dual-fuel during maximum operating conditions. It is clear that the dual-fuel establishes an overall superiority over the diesel, and the $\mathrm{NO}_{x}$ concentration in the exhaust gases for dual-fuel, on average, is 54\% lower than diesel. However, during the no-load operating condition this trend is generally inverted. For the no-load operating conditions, the $\mathrm{NO}_{\mathrm{x}}$ emission was higher with the dual-fuel operation during high-speed than with diesel operation. This is due to the higher air-fuel ratio and higher combustion temperatures (Yusaf et al., 2000). As the speed increases, the diesel fuel engine is running at a lower air to fuel ratio compared to dual-fuel, which means the reduction of oxygen intake. Therefore, to reduce the $\mathrm{NO}_{\mathrm{x}}$ emissions for dual-fuel the CNG injection should be increased. Another method is to reduce the airflow, making the mixture richer than that under normal dual-fuel operation. This can be done by throttling the intake air at light loads using the more sophisticated control of an electric control unit (ECU). Another solution is to mix CNG with only part of the incoming airflow (Dong et al., 1993). Nevertheless, in the application of power generation the no-load condition is only a very small proportion of its operation. At maximum engine torque, @ $2000 \mathrm{rpm}$, dual-fuel has a clear-cut superiority (less $\mathrm{NO}_{\mathrm{x}}$ ), at all applied torques, over the diesel.

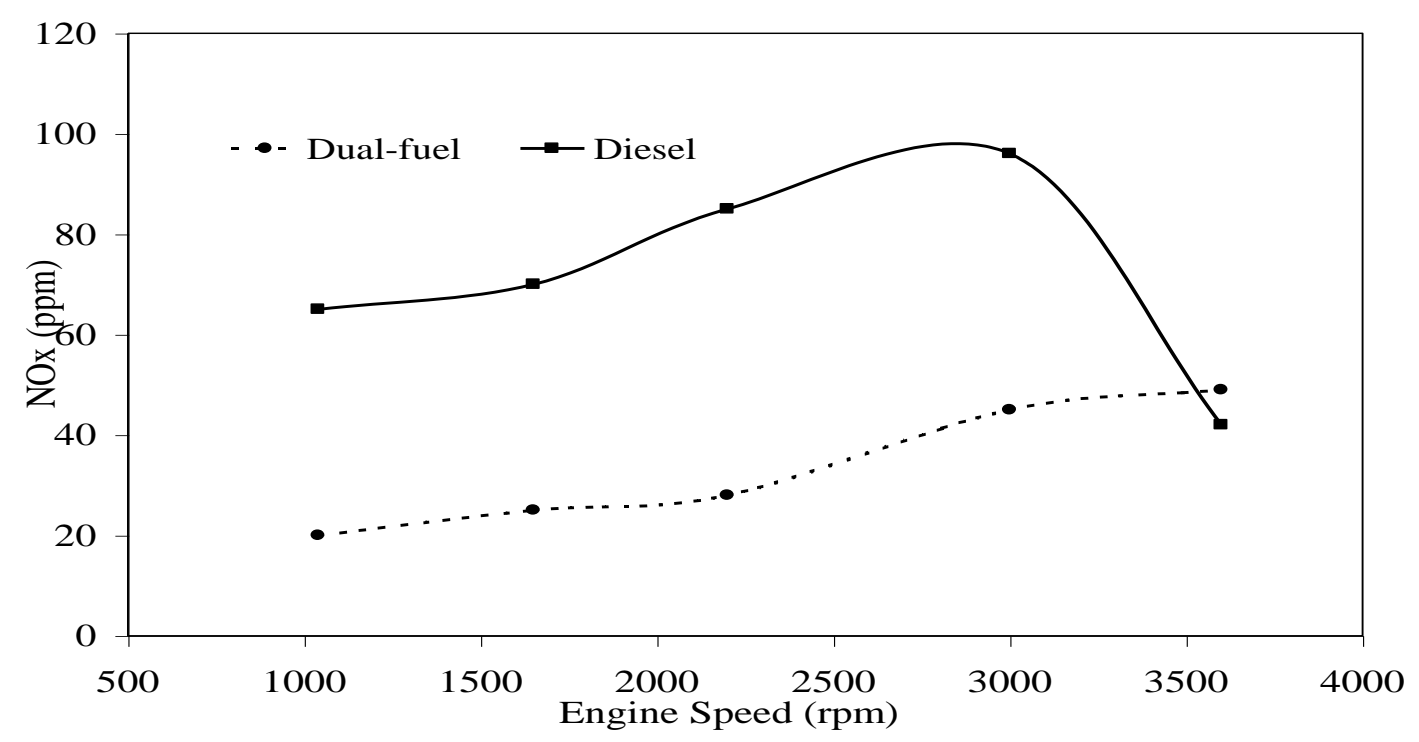

Figure 8. Variations of $\mathrm{NO}_{\mathrm{x}}$ with engine speed when set at maximum load operating conditions 


\section{Carbon Monoxide}

For the maximum operating condition, the $\mathrm{CO}$ for dual-fuel is $59 \%$ lower than for diesel, as shown in Figure 9. Generally, the dual-fuel runs better than diesel at maximum-load operating conditions. This shows that the dual-fuel can achieve better combustion at higher loads compared to diesel. The $\mathrm{CO}$ emission from dual-fuel under light operating conditions tended to be higher than that of diesel. At a constant engine speed of $2000 \mathrm{rpm}$, the dual-fuel starts to represent an improvement only at torques higher than $16 \mathrm{Nm}$. CO is usually attributed to a high equivalence ratio and/or poor mixing. With the straight diesel, this would indicate that as the load increases, the combustion approaches the smoke line as additional fuel is injected. With the dual-fuel engine, this rapid rise in $\mathrm{CO}$ does not occur, indicating a more efficient combustion with the addition of the premixed $\mathrm{CNG} /$ air charge, and lowering the requirement for additional diesel fuel (Akihiro et al., 2000).

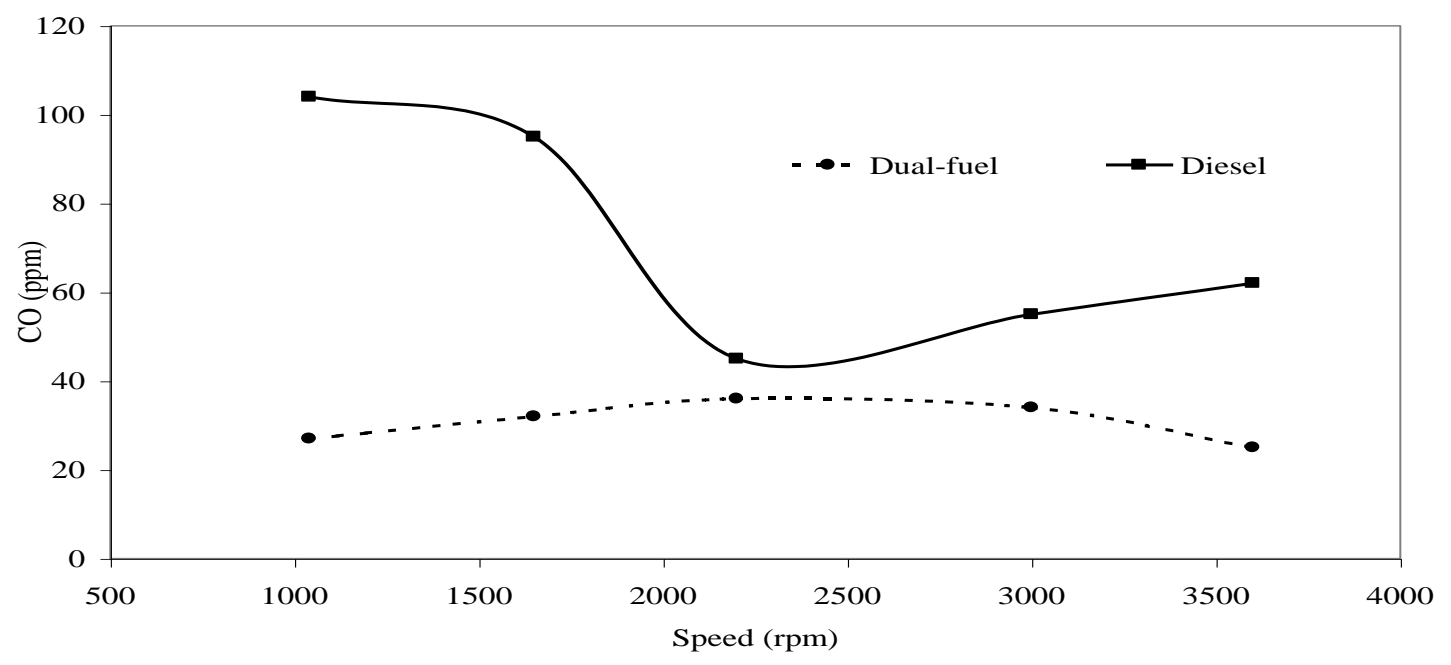

Figure 9. Variations of $\mathrm{CO}$ with engine under maximum load operating conditions

\section{Carbon Dioxide}

$\mathrm{CO}_{2}$ concentration in the exhaust gases is mainly a function of the chemical composition of the fuel and its hydrogen to carbon ratio, and the efficient conversion of $\mathrm{CO}$ to $\mathrm{CO}_{2}$ via the chemical kinetic reaction path. The hydrogen to carbon ratio for diesel fuel is 1.8:1 compared to 4:1 for methane (the main component of CNG). When the theoretical chemical combustion equations at stoichiometric are calculated for the combustion of $\mathrm{CH}_{4}$ and $\mathrm{C}_{\mathrm{n}} \mathrm{H}_{1.8 \mathrm{n}}$, then it works out that for every kilogram of diesel burned, $3.18 \mathrm{~kg}$ of $\mathrm{CO}_{2}$ is produced and for every kilogram of $\mathrm{CH}_{4}$ burned, $2.74 \mathrm{~kg}$ of $\mathrm{CO}_{2}$ is produced. This represents a theoretical reduction of $13.84 \%$ (mass basis) for a $100 \%$ combustion efficiency at stoichiometric. Test results for maximum operating conditions (Figure 10) show that the dual-fuel system gave consistently lower $\mathrm{CO}_{2}$ emission at maximum operating conditions throughout the entire speed range, with greater divergence at higher speeds. At the maximum operating condition, the dual-fuel gave an average of $31 \%$ less $\mathrm{CO}_{2}$ emission than diesel, as shown in Figure 10. On the other hand, the no-load operating conditions resulted in $5 \%$ reduction in $\mathrm{CO}_{2}$ emission when using the dual-fuel compared to the diesel. At the constant engine speed of 2000 
rpm, dual-fuel gave lower $\mathrm{CO}_{2}$ emission at all the tested torques with an average reduction of $18 \%$ compared to diesel. The results obtained in most cases returned better than theoretical reductions. This could be due to low conversion from $\mathrm{CO}$ to $\mathrm{CO}_{2}$, but the above results of $\mathrm{CO}$ would negate this. Another reason for the extra low reduction in $\mathrm{CO}_{2}$ emissions could be inefficient combustion due to a high equivalence ratio of the straight diesel system, resulting in higher $\mathrm{CO}$ and $\mathrm{CO}_{2}$ emissions. The foregoing results would tend to support this position.

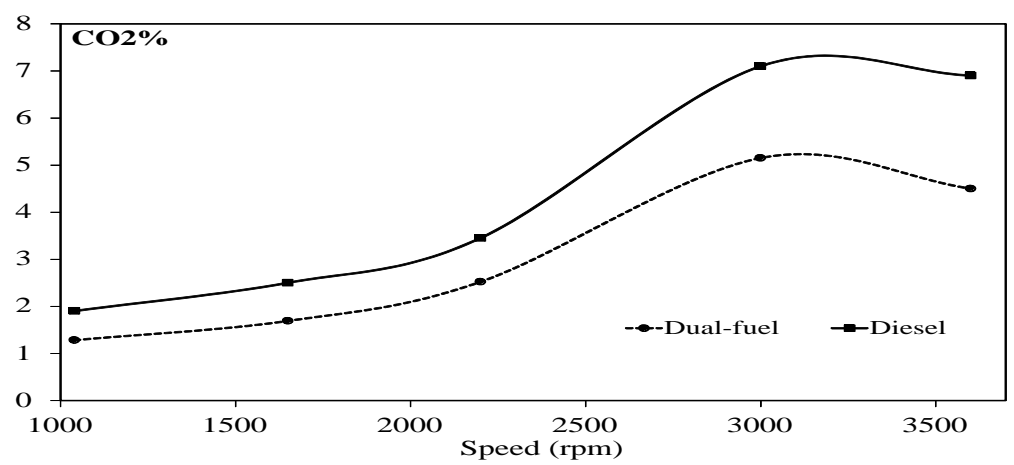

Figure 10. $\mathrm{CO}_{2}$ emissions as a function of engine speed for dual-fuel and diesel at maximum-load operating conditions operating conditions

\section{CONCLUSIONS}

A CNG-air Venturi mixer for a CNG-diesel dual-fuel stationary engine has been designed using 3D CFD analysis. Venturi mixers with four and eight holes have been simulated. It was found that the 8-hole Venturi mixer gives better mixing performance than the 4-hole mixer. This study shows that the conversion of an existing small singlecylinder stationary diesel engine to a dual-fuel system can be done with minimum modification. Tests showed that the emission of $\mathrm{CO}_{2}$ consistent with theory was less for dual-fuel than for diesel at all operating conditions. Maximum-load operating conditions yielded the best results, with $31 \%$, compared to only $5 \%$ at no-load. At maximum load, both $\mathrm{NO}_{\mathrm{x}}$ and $\mathrm{CO}$ emissions were less for dual-fuel compared to diesel by $54 \%$ and $59 \%$ respectively. However, at no-load operating conditions tests showed that diesel has an advantage over the dual-fuel. It has been convincingly demonstrated that a power generator CI engine fitted with a CNG dual-fuel system will have a positive impact on its environment due to a sizeable reduction in exhaust emissions with little or no loss of performance. The Venturi mixer system was proven to be a simple but effective method of converting a diesel engine generation set to dual- fuel.

\section{ACKNOWLEDGMENTS}

The authors would like to thank the University of Southern Queensland (USQ) for providing financial support and laboratory facilities. 


\section{REFERENCES}

Akansu, S. O., Dulger, Z., Kahramana, N., \& Veziroglu, T. N. (2004) Internal combustion engines fueled by natural gas-hydrogen mixtures. International Journal of Hydrogen Energy, 29, 1527-1539.

Akihiro, N., Ryouichi, K., Akio, I., \& Masao, U. (2000). Low emission and fuel efficient dual fuel diesel engines. International Association of Natural Gas Vehicle, Yokohama, Japan, Nov. 2-6

Azad, A. K., Ameer Uddin, S. M., \& Alam, M. M. (2012). A comprehensive study of DI diesel engine performance with vegetable oil: an alternative boi-fuel source of energy. International Journal of Automotive and Mechanical Engineering, 5, 576-586.

Aziz, A. R. A., Firmansyah, \& Shahzad, R. (2010). Combustion analysis of a CNG direct injection spark ignition engine. International Journal of Automotive and Mechanical Engineering, 2, 157-170.

Baker, P. A. (2009). LPG: A comparison of multipoint liquid and gaseous phase injection ( $\mathrm{PhD}$ Thesis). University of Melbourne.

Baukal, C. E., Gershtein, V. Y., \& Li, X. (2001). Computational fluid dynamics in industrial combustion. CRC Press.

Bhaskar, K., Nagarajan, G., \& Sampath, S. (2010). Experimental investigation on cold start emissions using electrically heated catalyst in a spark ignition engine. International Journal of Automotive and Mechanical Engineering, 2, 105-118.

Brook, J. R., Urch, B., Vincent, R., Rajagopalan, S., \& Silverman, F. (2002). Air pollution causes healthy blood vessels to constrict. Journal of the American Heart Association.

Carlucci, A. P., de Risi, A., Laforgia, D., \& Naccarato, F. (2008). Experimental investigation and combustion analysis of a direct injection dual-fuel diesel-natural gas engine. Energy, 33, 256-263.

Dally, B. B., Fletcher, D. F., \& Masri, A. R. (1998). Flow and mixing fields of turbulent bluff-body jets and flames. Combustion Theory and Modeling, 2, 193-219.

Das, A. (1995). Optimization of a natural gas spark ignition engine ( $\mathrm{PhD}$ thesis). University of Melbourne.

Davidson, D. L. (2002). The role of computational fluid dynamics in process industries. The Bridge, 32(4), 9-14.

Dong, S. J., Sung, W. S., Seung, M. O., \& Kyo, N. C. (1993). Development of a mechanical CNG-diesel dual fuel system. SAE Technical Paper Series (931947)

Fletcher, D., Haynes, B., Christo, F., \& Joseph, S. (2000). A CFD based combustion model of an entrained flow biomass gasifier. Applied Mathematical Modeling, 24, 165-182.

Ghobadian, B., Najafi, G., \& Nayebi, M. (2013). A semi-empirical model to predict diesel engine combustion parameters. Journal of Mechanical Engineering and Sciences, 4, 373-382.

Gourara, A., Roger, F., Wang, H. Y., \& Most, J. M. (2006). Assessment of ignition hazard in turbulent flammable gas mixers combining a Lagrangian approach and large eddy simulation. Combustion and Flame, 144, 592-604.

Heywood, J. B. (1988). Internal combustion engine fundamentals. McGraw-Hill.

Holmen, B. A. \& Ayala, A. (2002). Ultrafine PM emissions from natural gas, oxidationcatalyst diesel, and particle-trap diesel heavy-duty transit buses. Environmental Science and Technology, 36(23), 5041-5050. 
Ingersoll, J. G. (1996). Natural gas vehicles. Lilburn, GA: Fairmont Press.

Jones, W. P. \& Launder, B. E. (1972). The prediction of laminarization with a two equation model of turbulence. International Journal of Heat and Mass Transfer, 15, 301-314.

Kalyani Radha, K., Naga Sarada, S., Rajagopal, K., \& Nagesh, E. L. (2011). Performance and emission characteristics of CI engine operated on vegetable oils as alternate fuels. International Journal of Automotive and Mechanical Engineering, 4, 414-427.

Kamil, M., Rahman, M. M., \& Bakar, R. A. (2011). Performance evaluation of external mixture formation strategy in hydrogen fueled engine. Journal of Mechanical Engineering and Sciences, 1, 87-98.

Kapilan, N., Ashok Babu, T. P., \& Reddy, R. P. (2010). Improvement of performance of dual fuel engine operated at part load, International Journal of Automotive and Mechanical Engineering, 2, 200-210.

Launder, B. E., \& Sharma, B. I. (1974). Application of the energy dissipation model of turbulence to the calculation of flow near a spinning disc. Letters in Heat and Mass Transfer, 1(2), 131-138.

Li, G. X. \& Yao, B. F. (2008). Nonlinear dynamics of cycle-to-cycle combustion variations in a lean-burn natural gas engine. Applied Thermal Engineering, 28(5-6), 611-620.

Lin, Z. \& Su, W. (2003). A study on the amount of pilot injection and its effects on rich and lean boundaries of the premixed CNG/air mixture for a CNG/diesel dual-fuel engine. International Journal of Global Energy, 20(3), 290-301.

Mat Yasin, M. H., Mamat, R., Sharma, K. V., \& Yusop, A. F. (2012). Influence of palm methyl ester (PME) as an alternative fuel in the multicylinder diesel engine. Journal of Mechanical Engineering and Sciences, 3, 331-339.

Mello, P., Pelliza, G., Cataluña, R., \& Silva, R. D. (2006). Evaluation of the maximum horsepower of vehicles converted for use with natural gas fuel. Fuel, 85(14-15), 2180-2186.

Mishra, D. P. (2007). Experimental studies of flame stability limits of CNG-air premixed flame. Energy Conservation and Management, 48, 1208-1211.

Mohanamurugan, S., \& Sendilvelan, S. (2011). Emission and combustion characteristics of different fuel in a HCCI engine. International Journal of Automotive and Mechanical Engineering, 3, 279-292.

Najiha, M. A., Rahman, M. M., Kamal, M., Yusoff, A. R., \& Kadirgama, K. (2012a) Minimum quantity lubricant flow analysis in end milling processes: a computational fluid dynamics approach. Journal of Mechanical Engineering and Sciences, 3, 340-345.

Najiha, M. A., Rahman, M. M., Yusoff, A. R., \& Kadirgama, K. (2012b). Investigation of flow behavior in minimum quantity lubrication nozzle for end milling processes. International Journal of Automotive and Mechanical Engineering, 6, 768-776.

Noor, M. M., Wandel, A. P., \& Yusaf, T. (2012a). A review of MILD combustion and open furnace design consideration. International Journal of Automotive and Mechanical Engineering, 6, 730-754

Noor, M. M., Wandel, A. P., \& Yusaf, T. (2012b). The modeling of the effect of air fuel ratio on unburned hydrocarbons for MILD combustion. Malaysian Postgraduate Conference, 7-9 Jul, Bond Uni., Gold Coast, Paper No. MPC2012-27, 159-163.

Noor, M. M., Kadirgama, K., Devarajan, R., Rejab, M. R. M., Zuki, N. M., \& Yusaf, T. F. (2008). Design of a high pressure compressed natural gas mixer for 1500cc 
engine. National Conference on Design and Concurrent Engineering, 28-29 Oct., Melaka, 435-438.

Rahim, R. Mamat, R., Taib, M. Y., \& Abdullah, A. A. (2012). Influence of fuel temperature on a diesel engine performance operating with biodiesel blended. Journal of Mechanical Engineering and Sciences, 2, 226-236.

Ramasamy, D., Bakar, R. A., Rahim, M. F., \& Noor, M. M. (2008). Comparative evaluation of a two stroke CNG mixer design using simulation and experimental techniques. Asia Power \& Energy Systems, 2-4 April, Langkawi, 359-362.

Selim, M. Y. E. (2004). Sensitivity of dual fuel engine combustion and knocking limits to gaseous fuel composition. Energy Conservation and Management, 45, 411-425.

Sukh, S., Graham, J., \& Striebich, R. (2001). Semi-volatile and particulate emissions from the combustion of alternative diesel fuels. Chemosphere, 42, 681-690.

Sundar Raj, C., \& Sendilvelan, S. (2010). Effect of oxygenated hydrocarbon additives on exhaust emission of a diesel engine. International Journal of Automotive and Mechanical Engineering, 2, 144-156.

Suthawaree, J., Sikdera, H. A., Jonesa, C. E., Katoa, S., Kunimia, H., Kabirb, A. N. M. H., \& Kajiia, Y. (2012). Influence of extensive compressed natural gas (CNG) usage on air quality. Atmospheric Environment, 54, 296-307.

Tao, L. Z. \& Mei, F. S. (2004). Study of CNG/diesel dual fuel engine's emissions by means of RBF neural network. Journal of Zhejiang University of Science, 5(8), 960-965.

Wandel, A. P., Smith, N. S. A., \& Klimenko, A. Y. (2003). Implementation of multiple mapping conditioning for single conserved scalar. International Conference on CFD, Springer-Verlag, 789-790.

Xu, B. Y. \& Furuyama, M. (1997). Visualization of natural gas-air mixing flow in the mixer of a CNG vehicle. JSAE Review, 18(1), 57-60.

Yanagisawa, R., Takano, H., Inoue, K., \& Ichinose, T. (2003). Enhancement of acute lung injury related to bacterial endotoxin by components of diesel exhaust particles. Thorax (NLM - Medline), 58(7), 605.

Yusaf, T. (2009). Experimental investigation of a single cylinder diesel engine as a hybrid power unit for a series hybrid electric vehicle. Journal of Energy Resources Technology, ASME, 131, 12203-12207.

Yusaf, T. F., Yusoff, M. Z., Ali, Y., Shamsuddin, A. H., \& Muda, M. K. (2000) Design of CNG mixer for stationary diesel engine using CFD. Int. Conf. on Fluid and Thermal Energy Conversion, Hyatt Regency, Bandung, Indonesia, July 2-6.

Yusaf, T. F., Buttsworth, D. R., Saleh, K. H., \& Yousif, B. F. (2010). CNG-diesel engine performance and exhaust emission analysis with the aid of artificial neural network. Applied Energy, 87, 1661-1669.

Yusaf, T. F., Shamsuddin, A. H., Ali, Y., \& Ismail, A. F. (1996). Design modification of high speed diesel engine to accommodate compressed natural gas. RERIC International Energy Journal, 8(1), 19-26.

Zhang, H. G., Han, X. J., Yao, B. F., \& Li, G. X. (2013). Study on the effect of engine operation parameters on cyclic combustion variations and correlation coefficient between the pressure-related parameters of a CNG engine. Applied Energy, 104, 992-1002. 